which items they valued most in letters. In order of relevance to the GPs the top most important letter items (mean rating score in parentheses) were diagnosis (1.00), presenting complaint (1.13), treatment recommendations (1.13), follow-up arrangements (1.18), mental state examination (1.45) and medication prescribed (1.63). It was interesting to note that overall no item was rated as irrelevant. Twenty-one of 45 (47\%) GPs believed the letters were too long, 23 $(51 \%)$ that they were adequate and only one $(2 \%)$ that they were too short. Forty out of 47 (85\%) said they did have time to read the letters, the other seven (15\%) did not. Most, 41 of $45(91 \%)$, received their letters quickly whereas four (9\%) claimed they did not, Eight GPs additionally advised that diagnosis, treatment recommendations and follow-up arrangements should be listed at the top of all letters.

DARREN REYNOLDS, Specialist Registrar in Old Age Psychiatry. Carisbrooke Resource Centre, Wenlock Way, Gorton, Manchester M12 5LF

\section{Minimum wage legislation}

Sir: I wish to draw the attention of College members to the implications of minimum wage legislation for sheltered employment projects. The Department of Trade and Industry advice is that such projects should now be paying workers the minimum wage. The effect of interpreting the act in this way is that as many as 10000 disabled people face the risk of losing their employment as many sheltered projects will be unable to fund wages at this level. Even if the projects were able to increase wage levels there would be no net gain to many who would find their benefits reduced accordingly.

It would seem that legislation aimed at promoting social inclusion is in reality having the effect of excluding some of the most vulnerable members of society from their current employment.

JON C. BARNES, Consultant Psychiatrist, Phoenix House, Priory Park, Glastonbury Road. Wells, Somerset BA5 1TH 